Available online at GSC Online Press Directory

GSC Biological and Pharmaceutical Sciences

e-ISSN: 2581-3250, CODEN (USA): GBPSC2

Journal homepage: https://www.gsconlinepress.com/journals/gscbps

(REVIEW ARTICLE)

\title{
Pharmacopoeial comparison of in-process and finished product quality control test for pharmaceutical tablets
}

\author{
Ghimire Prakash ${ }^{1,}{ }^{*}$, Shrestha Abinash Chandra ${ }^{2}$, Pandey Sandhya ${ }^{3}$, Chapagain Bidur ${ }^{4}$ and Dhakal Samir 5 \\ ${ }^{1}$ Universal College of Medical Sciences, Tribhuvan University, Ranigaon, Bhairahawa, Rupandehi, Nepal. \\ ${ }^{2}$ College of Pharmacy, Woosuk University, Wanju, Jeonbuk 55338, Republic of Korea. \\ ${ }^{3}$ Australian Catholic University, North Sydney, Australia. \\ ${ }^{4}$ Little Buddha College of Health Science, Purbanchal University, Kathmandu, Nepal. \\ ${ }^{5}$ Krupanidhi College of Pharmacy, Rajiv Gandhi University, Varthur Hobli, Bangalore, India.
}

Publication history: Received on 10 June 2020; revised on 18 June 2020; accepted on 21 June 2020

Article DOI: https://doi.org/10.30574/gscbps.2020.11.3.0174

\begin{abstract}
All Pharmaceutical industries endeavour to produce good quality products which are achieved by allowing in-process and finished product quality control approaches. In-process quality control is concepts that are carried out before, after and during production covering all steps, counting the establishment of specifications, sampling, relevant testing and analytical clearance assuring that the intermediates, packaging materials and finished pharmaceutical tablets conform with approved specifications or standard for efficacy, safety and elegance which assure the consumer that the products perform consistently and in a manner satisfactory for the purpose for which it is recommended. Quality control highlights testing of products for defects which ease the producer to refuse the releases of products or carry out the possible investigation to make pharmaceutical tablets perfect before released into the market. Since different pharmacopoeias have set the diverse specified limits to some extent within which the value ought to fall with respect to be acquiescent as per the standards. Hence by comparing pharmacopoeias, an effort is made to convey the harmonized limits so that the products should meet the requirements as specified in pharmacopoeias specification to confirm the quality of pharmaceutical dosage form. The endeavour of this study is to compare various quality control assessments for pharmaceutical tablets according to different pharmacopoeias standards.
\end{abstract}

Keywords: In-process quality control; Finished product quality control; Pharmaceutical tablets; Pharmacopoeia; Specification

\section{Introduction}

Quality is a broad term which cannot be tested into the product; it should be built into it [1]. The quality of pharmaceutical manufacturing has turned into a crucial and delicate subject. Since the togetherness of globe to amalgamate its practices, steers and the introduction of the Food and Drug Administration (FDA) current good manufacturing practices (cGMP) for the 21st century- the alertness for the consequence of the quality of the medicinal products has been heaved up. The manufactured goods are considered as "fit for use" only when it complies with its established quality attributes and standards [2].

Quality is an intelligent effort which ensures the aptness of drugs and medicines for their intended use based on their safety and efficacy, according to the label claim, or as upgraded or revealed their compliances to specification concerning identity, strength, purity and other attributes [3].

\footnotetext{
* Corresponding author: Ghimire Prakash
} 
The products manufactured under the Good Manufacturing practices (GMP) conditions or requirements, ensured the high level of quality and safety of the product. Both production and quality control (QC) are brought under the roof of GMP [4]. QC being an integral section of GMP, the quality of all aspects involved in manufacturing, is analyzed by QC personnel to abolish blunders at each step in manufacturing. The rationales of QC are to produce an ideal product by averting or eradicating faults at each phase in production. Quality must be built into medicines during production and designing of a process which is achieved by the proper spacing, ventilation, design of the plant, sanitation and hygiene during schedule fabrication of products [5].

To confirming the quality of pharmaceutical dosage form, it is required to perform the quality control test as prescribed in various pharmacopoeias and guidelines [6]. The International Standard of Organization (ISO) defines quality control as "the operational techniques and activities that are useful to fulfil requirements for quality". This definition proposes that every bustle related to control, enhancement, management or assurance of quality might be accomplished by the quality control test [3].

Quality control of medicinal products is a notion that swathes all measures taken, including the establishment of specifications, sampling, relevant testing and analytical clearance, to make certain that the starting materials, intermediates, packaging materials and finished pharmaceutical products conform with approved specifications or standard for identity, strength, purity and other attributes [7]. Quality control accentuates testing of products for blemish, which ease the producer to refuse the releases of products or carry out the possible investigation to make products absolutely unblemished prior to released into the market [8].

In-process quality control ensures that the product complies with all the quality requirements, principally safety of a product and all operations that are carried out before, during and after the manufacturing of a finished product, from receiving raw materials, processing, packaging and labelling until the end of the batch are controlled [9]. The physical parameters and quality attributes of in-process materials should undergo various quality control assessments which help quality control department to make decisions for their approval or rejection. To prevent the use of rejected inprocess materials in the manufacturing, it should be identified and controlled under a quarantine system [8].

In-process quality control represents the monitoring and evaluation of manufacturing process to produce medication of superior efficacy, safety and elegance which assure the consumer that the products perform consistently and in a manner satisfactory for the purpose of its intended use [10].

The quality control assessment is carried out to control the quality of products which begins from starting materials, processing, packaging, labelling and finished product testing as well as batch reviewing and stability monitoring. The control on all maneuvers should be established in the structure of a written procedure which noticeably explains to follow the IPQCs and tests. Written procedures are known as Standard operating procedures (SOPs) [9].

During the manufacturing and formulation development of tablets, a number of the procedures are employed to assess the quality of tablets. Some tests are described in pharmacopoeias which are traditionally concerned with content and in vivo release of active substances, while other than pharmacopoeias are known as non-compendia test concerning with quality attributes and need to be used in quality evaluation of tablets [6]. Finished products are those dosage forms that have undergone every phase of production, including the packaging in its final container and labelling [7]. The FPQC test with respect to qualitative and quantitative characteristics along with test procedures and their acceptance limits as described in specification by which the finished product should comply throughout its valid expiration date [8].

The specification of the finished product is determined by the quality attributes related to the process of production. During the developmental phase and at the time of validation of the manufacturing process, a suitable specification for every facet of the quality studied should be dogged regularly [11]. During or after the manufacturing process, certain IPQC and FPQC assessment are performed where the acceptance criterion is the same or minimal than the release requirement, (e.g. size, shape, weight, hardness, thickness, disintegration, dissolution and other characteristics) which may serve as a foundation for quality evaluation when included in the specification [8].

In the globe, different countries have diverse pharmacopoeias, such as Indian Pharmacopoeia (IP), British Pharmacopoeia (BP), United States Pharmacopoeia (USP), European Pharmacopoeia (PhEur), International Pharmacopoeia (PhInt) and Japanese Pharmacopoeia (JP). Since different pharmacopoeias have laid down the diverse specified limits to some extent within which the value should fall in order to be acquiescent as per the standards. This study has been done to show the quality parameters for pharmaceutical tablets according to the pharmacopoeias that are an element of in-process and finished products quality control tests. 


\section{Universal test for the pharmaceutical tablets dosage form}

It is estimated that at least $90 \%$ of drugs administered by oral route out of which tablets and capsule result in the high reduction of medication error in dose measurement when the drug is self-administered by the patient [12].

The four tests are likely to relevant to tablets dosage form and other pharmaceutical products: Description, Identification, Assay and Impurity.

\subsection{Description}

This test is a qualitative description of the appearance of tablets depicts on a specification. For example, specification illustrates the tablets as an: white, round, biconvex, film-coated tablet, embossed with "drug strength (Rx)" on the single side [13].

\subsection{Identification}

The objective of an identification or identity test is to substantiate the identity of the active pharmaceutical ingredient(s) (API) and to distinguish the compound(s) that is closely related in structure as that of compounds that are likely to be present in pharmaceutical tablets [13]. The British Pharmacopoeia 2014, however, does not regard identification solely sufficient to establish absolute proof of identity [14].

\subsection{Assay}

This tests also known as a content test and is used to conclude the strength or content of the active pharmaceutical ingredients present in the tablets. This method is specific and quantitative to detect chemical changes over time and thus taken as a stability-indicating test [13].

\subsection{Impurities}

This test often considered as purity test and stability-indicating test, which measures the presence of component other than API or an excipients. The primarily prevalent form of impurities that calculate is related substances ensuing from a chemical transformation in the drug substance fetched about during manufacture and/or storage of the new drug product $[13,15]$.

\section{In-process and finished product quality control test for the tablets dosage form}

Various parameters that can be controlled by in-vitro testing during tablet production include the moisture content of granules, size of granules, moisture content, loss on drying, flow of final blend, etc.. Finished product quality control test for tablets are dimensions (thickness, diameter), assay, uniformity of content, weight variation, friability test, the content of active ingredients, hardness test, disintegration test, dissolution test etc. [16].

\subsection{Quality control test for tablets: non-compendial standards}

There are frequent numbers of tests applied to tablets which are not included in official pharmacopoeias and will be based on the manufacturer's own product specification.

\subsubsection{General appearance}

The general appearance of the tablet can be controlled by assessment of a number of features such as tablet's dimensions (size and shape), colour, odour, taste, texture, readability of any identifying markings [12].

\subsubsection{The moisture content of granules}

In wet granulation, granules are held together by bonds of particular strength which is mainly due to moisture content in a powder of particulate materials. Moreover, a convinced \% of moisture content influences the process of size reduction, flowability and compressibility of powder. E.g. too dry granules tend to cap or laminate during compression of tablets [6].

\subsubsection{Size and shape}

The qualities of tablets are able to be dimensionally portrayed, monitored and controlled by assessing the shape and size of tablets. During the compression process, it is determined by tooling [12]. 


\subsubsection{Thickness}

The consistency in manufacturing process like-granulation, particle size, size distribution, powder mixing etc. is determined by measuring thickness [12]. It is determined by tooling (e.g. Die's diameter, the internal volume of dies, compressibility of powder, the force or pressure, etc.) during the compression process. The thickness of entity tablets may be deliberate by a micrometre or any other automated types of equipment [17]. The thickness of the tablet should be controlled within a range of $\pm 5 \%$ deviation of a standard to smooth the progress of packaging, which is expressed in $\mathrm{mm}$ (millimetre) [12].

\subsubsection{Unique identification marking}

Pharmaceutical industries exploit some type of embossing, engraving or printing as some forms of unique marks apart from the addition of colour. These markings embrace company name or logo, product code, drug strength, product name etc. on tablets [12].

\subsubsection{Organoleptic properties (colour, odour and taste)}

Many pharmaceutical companies impart colour on tablets for rapid identification and consumer acceptance. Colour distribution ought to be homogeneous without mottling. For visual colour, evaluation compares the colour of the sample next to the standard colour. The odour might be a stability-indicating parameter. E.g. the characteristic aroma of acetic acid indicate degradation of aspirin tablets. Taste is another attribute for patient compliance. E.g. Suitable taste in chewable tablet increase patient compliance [12].

\subsubsection{Hardness}

Hardness may be vital criterion since, it affects the friability, disintegration, and dissolution of tablets. Tablet entails a certain amount of hardness and resistance to friability to withstand abrasion in handling, packaging, and transportation. The extent of pressure during compression, characteristic of granulation affects the hardness of tablets. Thus, to control a tablet's hardness, it's important to control pressure. Hardness is measured by hardness tester-the Monsanto tester, the Pfizer tester, the Erweka tester, the Schleuniger tester; or a multifunctional system $[12,17]$. The tablets are typically positioned between two platens, where one is constant, and other moves apply ample power to cause fracture of a tablet. The loading of round and conventional tablets takes place across their diameter (as a diametrical loading) where breakage occurs therein plane [18]. Hardness generally measures crushing strength (in kilogram, pound or arbitrary units) which should be more than $4 \mathrm{~kg}$ [17].

\subsection{Quality control test for tablets dosage form -pharmacopoeial standards}

\subsubsection{Friability}

A compressed and uncoated tablets strength and durability may be determined through the use of friabilator [17] mostly by Roche friabilator [12]. For this test, tablets with an average weight of $\leq 650 \mathrm{mg}$ and greater than $650 \mathrm{mg}$, sample of entire tablets equivalent to about $6.5 \mathrm{~g}$ and a sample of 10 whole tablets respectively are weighed, dedusted and placed in drum of friabilator where it is rotated for 100 times. The friability value is expressed in percentage, which is calculated by using the subsequent formula:

$$
\text { Friability }=\frac{(\mathrm{Wi}-\mathrm{Wf})}{\mathrm{Wi}} \times 100
$$

Where, $\mathrm{Wi}=$ Total initial mass of tablets; $\mathrm{Wf}=$ Total final mass of tablets.

Generally, the test is run only once but in case of difficulty in interpretation of the result, or if final weight loss is higher than the targeted value, the test can be replicated twice, and the result is expressed as a mean of the three tests. Apart from cracked, chipped, broken of tablets, if weight loss of rolled (after 100 times revolution) tablets is more than $1 \%$ then the test is not acceptable $[14,18,19]$.

\subsubsection{Disintegration test}

This test is to determine the act of breaking down of tablets into smaller particles or into constituent elements within the prescribed time when placed in a liquid medium under the described experimental conditions $[14,18,19]$.

The USP \& BP disintegration apparatus consists of six open-ended transparent tubes having a length of $77.5 \pm 2.5 \mathrm{~mm}$, the internal diameter of $21.85 \pm 1.15 \mathrm{~mm}$, a wall thickness of $1.9 \pm 0.9 \mathrm{~mm}[14,18]$ while the IP disintegration apparatus 
consists of six open-ended transparent tubes with $77.5 \pm 2.5 \mathrm{~mm}$ long, the internal diameter of $21.5 \mathrm{~mm}$, the wall thickness of about $2.0 \mathrm{~mm}$ [19]. This seamless tube was held at the bottom end of the basket rack assembly against a 10-mesh screen. To assess the time of disintegration, a single tablet is positioned in every tube, and the basket rack is placed in particular liquid medium at a temperature of $37 \pm 2{ }^{\circ} \mathrm{C}$ (unless otherwise specified in the individual monograph) in an apt vessel, preferably a 1-litre beaker such that when the assembly is within the outmost position the wire mesh is at least $15 \mathrm{~mm}$ beneath the surface of the liquid, and when the assembly is in the lowest position the wire mesh is at least $25 \mathrm{~mm}$ above the base of the beaker, and therefore the upper open ends of the tubes remain above the surface of the liquid. The top of basket rack assembly should not be submerged in medium. A standard motor-driven tool is used to move the basket assembly containing the tablets up and down through a distance of $5.5 \pm 0.2 \mathrm{~cm}$ at a frequency of 28 to 32 cycles per minute [14,19]. Perforated plastic discs may also be used in the test. Introduce one tablet in each of 6 tubes of the basket, and if prescribed, perforated plastic discs may also be used in the test.

The tablets conform to the test if no any residue retains on 10-mesh screen in a specified time frame. If present, they should be soft mass having no palpably firm core $[14,19]$. If 1 or 2 tablets (out of 6 tablets) not succeed to disintegrate then a trial is repeated on 12 extra tablets. Complies with the test are denoted if at least 16 are disintegrated out of 18 tablets. The pharmacopoeias limits for disintegration times frame of tablets along with the liquid medium and the operating temperature are given in table 1 and $2[14,18,19]$.

Table 1 IP/BP limits for disintegration time of tablets (unless otherwise specified in the individual monograph)

\begin{tabular}{|c|c|c|c|c|}
\hline Types of tablets & Medium & Temperature $\left({ }^{\circ} \mathrm{C}\right)$ & Time (Minutes) & Pharmacopoeia \\
\hline Uncoated Tablets & Water & $37 \pm 2$ & 15 & $\mathrm{IP} / \mathrm{BP}$ \\
\hline $\begin{array}{l}\text { Coated Tablets (Other } \\
\text { than film coated) }\end{array}$ & Water & $37 \pm 2$ & 60 & $\mathrm{IP} / \mathrm{BP}$ \\
\hline Film-coated Tablets & Water & $37 \pm 2$ & 30 & $\mathrm{IP} / \mathrm{BP}$ \\
\hline Dispersible Tablets & Water & $20 \pm 5$ & 3 & IP/BP \\
\hline Effervescent Tablets & $\begin{array}{l}200 \mathrm{ml} \text { of non-agitated } \\
\text { water }\end{array}$ & $20 \pm 5$ & 5 & IP/BP \\
\hline \multirow[t]{2}{*}{ Enteric-coated Tablets } & $\begin{array}{l}0.1 \mathrm{~N} \mathrm{HCl} / \text { as specified in } \\
\text { individual monograph }\end{array}$ & $37 \pm 2$ & $\begin{array}{l}\text { No evidence of } \\
\text { disintegration } \\
\text { after } 2 \text { hours }\end{array}$ & IP/BP \\
\hline & $\begin{array}{ll}\text { Phosphate } & \text { buffer } \\
\text { solution } \mathrm{pH} 6.8 & \end{array}$ & $37 \pm 2$ & 60 & \\
\hline Soluble Tablets & Water & $20 \pm 5$ & 3 & IP/BP \\
\hline Oral Lyophilisates & $\begin{array}{l}200 \mathrm{~mL} \text { of non-agitated } \\
\text { water }\end{array}$ & $20 \pm 5$ & 3 & $\mathrm{BP}$ \\
\hline Orodispersible Tablets & Water & $37 \pm 2$ & 3 & $\mathrm{BP}$ \\
\hline
\end{tabular}


Table 2 USP limits for disintegration time of tablets (unless otherwise specified in the individual monograph)

\begin{tabular}{|c|c|c|c|}
\hline Types of tablets & Medium & Temperature $\left({ }^{\circ} \mathrm{C}\right)$ & Time (Minutes) \\
\hline Uncoated Tablets & $\begin{array}{l}\text { Water/ as specified in the } \\
\text { individual monograph }\end{array}$ & $37 \pm 2$ & $\begin{array}{l}\text { As specified in the } \\
\text { individual monograph }\end{array}$ \\
\hline $\begin{array}{l}\text { Plain Coated } \\
\text { Tablets }\end{array}$ & $\begin{array}{l}\text { Water/ as specified in the } \\
\text { individual monograph }\end{array}$ & $37 \pm 2$ & $\begin{array}{l}\text { As specified in the } \\
\text { individual monograph }\end{array}$ \\
\hline $\begin{array}{l}\text { Delayed-Release/ } \\
\text { Enteric-coated }\end{array}$ & Simulated gastric fluid TS & $37 \pm 2$ & $\begin{array}{l}\text { No evidence of } \\
\text { disintegration after } 1 \text { hour }\end{array}$ \\
\hline Tablets & Simulated intestinal fluid TS & $37 \pm 2$ & $\begin{array}{l}\text { As specified in the } \\
\text { individual monograph }\end{array}$ \\
\hline Buccal Tablets & $\begin{array}{l}\text { Water/ as specified in the } \\
\text { individual monograph }\end{array}$ & $37 \pm 2$ & After 4 hours \\
\hline Sublingual Tablets & $\begin{array}{l}\text { Water/ as specified in the } \\
\text { individual monograph }\end{array}$ & $37 \pm 2$ & $\begin{array}{l}\text { As specified in the } \\
\text { individual monograph }\end{array}$ \\
\hline
\end{tabular}

For those uncoated or coated tablets for which a requirement for dissolution is included in the individual monograph, the requirement for disintegration does not apply [14].

\subsubsection{Uniformity of dosage units}

The uniformity of dosage units can be presented by whichever of two methods: Content Uniformity and Weight Variation.

\section{Weight variation test}

This test applies for uncoated and coated tablets where 20 tablets are weighed individually and calculated the average mass. The requirements to weight variation are met if the weight of not more than two of tablets deviates from average weight by greater than the percentage listed in table 3 and 4 and no tablets vary in weight by more than two-fold of that percentage $[14,18,19]$.

The result of this test is expressed in percentage and calculated from the given formula:

$$
\text { Weight Variation }=\frac{(\mathrm{WI}-\mathrm{WA})}{\mathrm{WA}} \times 100
$$

Where,

WI = Individual tablet's weight; WA = Average tablet's weight.

Table 3 Weight variation tolerance for uncoated and film-coated tablets as per IP, BP and USP

\begin{tabular}{lll}
\hline IP/BP & Percentage Deviation (\%) & USP \\
\hline $80 \mathrm{mg}$ or less & 10 & $130 \mathrm{mg}$ or less \\
$\begin{array}{l}\text { More than } 80 \mathrm{mg} \text { and less than } \\
250 \mathrm{mg}\end{array}$ & 7.5 & More than $130 \mathrm{mg}$ and less than $325 \mathrm{mg}$ \\
$250 \mathrm{mg}$ or more & 5 & $325 \mathrm{mg}$ or more \\
\hline
\end{tabular}


Table 4 Weight variation tolerance for uncoated and film-coated tablets containing 5\% or more of active ingredient (International Pharmacopoeia)

\begin{tabular}{lll}
\hline International Pharmacopoeia & Percentage Deviation (\%) & Number of tablets \\
\hline Less than $80 \mathrm{mg}$ & 10 & Minimum 18 \\
& 20 & Maximum 2 \\
$80 \mathrm{mg}$ to $250 \mathrm{mg}$ & 7.5 & Minimum 18 \\
& 15 & Maximum 2 \\
More than $250 \mathrm{mg}$ & 5 & Minimum 18 \\
& 10 & Maximum 2 \\
\hline
\end{tabular}

As per International Pharmacopoeia, a test for "Uniformity of Content" can be applied, if film-coated tablets fail to comply with this test of weight variation.

The dosage form is not submitted to test for uniformity of weight but subjected to the test for uniformity of content when the active ingredient in a tablet is $\leq 10 \mathrm{mg}$, the average weight of tablets is $\leq 40 \mathrm{mg}$ and dose, or ratio of drug substance to tablet's weight is $<25 \mathrm{mg}$ or $<25 \%$ according to IP, BP and USP respectively.

Uniformity of content

According to USP/BP, this test is based on assay of individual content of drug substance(s) in 10 tablets taken randomly to determine whether the amount of drug from batch to batch and tablet to tablet is within a narrow range around the label claim $[14,18]$.

According to BP, the tablet complies if all individual content is within the limits of 85 to $115 \%$ and none deviate from the limits of 75 to $125 \%$ of the average content. If one individual's content is outside the limits of $85 \%$ to $115 \%$, but within the limits of $75 \%$ to $125 \%$, determine the individual contents of an additional 20 tablets. The tablet fulfills the requirements with the test if not more than one of the individual contents of the 30 tablets is outside $85 \%$ to $115 \%$ of the average content and none is outside the limits of $75 \%$ to $125 \%$ of the average content [14].

\subsubsection{Content of active ingredients}

As per IP, the totality of active ingredient(s) per tablet is calculated by following the procedure as described in the assay. The result lies within the range for the content of active ingredient(s) stated in the monograph. This limit is given for that of 20 tablets, or such other number as may be pointed out in the monograph, are used in the assay. In case 20 tablets cannot be obtained then a lesser number, which should not be fewer than five tablets, may be used, but to permit for sampling errors the tolerances are broadened in accordance with table 5 [19].

Table 5 Tolerances to allow for sampling errors as per IP

\begin{tabular}{lllllll}
\hline $\begin{array}{l}\text { Weight of active ingredients in each } \\
\text { tablet }\end{array}$ & $\begin{array}{l}\text { Subtract from the lower limit } \\
\text { for samples of }\end{array}$ & \multicolumn{4}{l}{$\begin{array}{l}\text { Add to the upper limit for } \\
\text { samples of }\end{array}$} \\
\cline { 2 - 7 } & 15 & 10 & 5 & 15 & 10 & 5 \\
\hline 0.12 g or less & 0.2 & 0.7 & 1.6 & 0.3 & 0.8 & 1.8 \\
More than 0.12 g but less than $0.3 \mathrm{~g}$ & 0.2 & 0.5 & 1.2 & 0.3 & 0.6 & 1.5 \\
0.3 g or more & 0.1 & 0.2 & 0.8 & 0.2 & 0.4 & 1.0 \\
\hline
\end{tabular}

\subsubsection{Assay}

In a tablet, an active ingredient is present, which is referred to as API. This test determines the strength or content of the API expected to be present in the pharmaceutical tablet calculated from the strength stated on the label by using a suitable analytical method $[19,20]$. Assay value is often calculated from the average of all individual's content 
uniformity, where content uniformity follows the similar analytical procedure specified in assay test with suitable allowances made for differences in sample preparation [18].

\subsubsection{Dissolution}

The BP, JP or USP dissolution apparatus I (Basket apparatus) and apparatus II (Paddle apparatus) consist of a transparent made of glass or inert cylindrical vessel with a hemispherical bottom, which may be covered, the capacity of $1 \mathrm{~L}$. Assembly of both apparatus differs only in stirring element where the basket is used in apparatus I and paddle are used in apparatus II. But this assembly is reversed in IP where apparatus I and II use paddle and basket respectively. The partially immersed vessel in a water bath is maintained with a temperature of $37 \pm 0.5^{\circ} \mathrm{C}$ during the test $[14,18,20]$.

For testing dissolution, the defined volume of dissolution medium $( \pm 1 \%)$ is placed in the vessel of the particular apparatus where the temperature is controlled at $37 \pm 0.5^{\circ} \mathrm{C}$ throughout the testing time frame. With care to exclude air bubbles from tablet surface, a single tablet is placed in apparatus and test is run for specified time interval where a sample is withdrawn from midway between the surface of dissolution medium and top of rotating basket or paddle, at least $1 \mathrm{~cm}$ from wall of a vessel. For specified several sampling times, aliquots withdrawn is replaced with fresh dissolution medium. Performed the analysis using a suitable dissolution medium and assay method as defined in the individual monograph and test is repeated with supplementary tablets. For buffered solution as a dissolution medium, the solution is adjusted so that its $\mathrm{pH}$ is with 0.05 unit of defined $\mathrm{pH}$. In respective of time, the specimens are withdrawn within a tolerance of $\pm 2 \%$ of the stated time.

According to BP, IP, USP, JP and PhInt, unless otherwise specified, the requirements are met if the quantities of active substance dissolved from the dosage units conform to table $6,7,8$ \& 9 [14, 18-20].

Table 6 Acceptance criteria for dissolution test of a tablet for immediate release tablets as per IP, BP, USP, JP, PhInt.

\begin{tabular}{lll}
\hline Stage & Number of tablets tested & Acceptance Criteria \\
\hline S1 & 6 & Each unit is not less than $Q+5 \%$. \\
S2 & 6 & $\begin{array}{l}\text { Average of } 12 \text { units }(\mathrm{S} 1+\mathrm{S} 2) \text { is equal to or greater than } \mathrm{Q} \text {, and } \\
\text { no unit is less than } \mathrm{Q}-15 \% .\end{array}$ \\
S3 & 12 & $\begin{array}{l}\text { Average of } 24 \text { units }(\mathrm{S} 1+\mathrm{S} 2+\mathrm{S} 3) \text { is equal to or greater than } \mathrm{Q}, \\
\text { not more than } 2 \text { units are less than } \mathrm{Q}-15 \% \text { and no unit is less } \\
\text { than } \mathrm{Q}-25 \% .\end{array}$ \\
\hline
\end{tabular}

Table 7 Acceptance criteria for dissolution test (pooled sample) of a tablet for immediate release tablets as per USP.

\begin{tabular}{|c|c|c|}
\hline Stage & Number of tablets tested & Acceptance Criteria \\
\hline S1 & 6 & Average amount dissolved is not less than $Q+10 \%$. \\
\hline $\mathrm{S} 2$ & 6 & $\begin{array}{l}\text { Average amount dissolved of } 12 \text { units }(\mathrm{S} 1+\mathrm{S} 2) \text { is equal to or } \\
\text { greater than } Q+5 \% \text {. }\end{array}$ \\
\hline S3 & 12 & $\begin{array}{l}\text { Average amount dissolved of } 24 \text { units }(\mathrm{S} 1+\mathrm{S} 2+\mathrm{S} 3) \text { is equal to or } \\
\text { greater than } \mathrm{Q} \text {. }\end{array}$ \\
\hline
\end{tabular}

Unless the results conform at either $\mathrm{S}_{1}$ orS 2 , continue testing through the 3 stages. The value $\mathrm{Q}$ (D in IP), is the specified quantity of dissolved active substance, expressed as a percentage of the labelled content [14, 18-22].

According to JP, when the value of Q or D is not specified in individual monograph and if one or two tablets fail to comply with the requirements, repeat the test on extra 6 tablets. To conform to the test, not less than ten tablets out of 12 should meet the requirements [20]. 
Table 8 Acceptance criteria for dissolution test of a tablet for Extended or Prolonged-release tablets as per USP, BP, JP, IP.

\begin{tabular}{|c|c|c|}
\hline Stage & Number of tablets tested & Acceptance Criteria \\
\hline L1 & 6 & $\begin{array}{l}\text { No individual value lies outside each of the stated ranges and no } \\
\text { individual value is less than the stated amount at the final test time. }\end{array}$ \\
\hline $\mathrm{L} 2$ & 6 & $\begin{array}{l}\text { The average value of the } 12 \text { units }(\mathrm{L} 1+\mathrm{L} 2) \text { lies within each of the } \\
\text { stated ranges and is not less than the stated amount at the final test } \\
\text { time; none is more than } 10 \text { per cent of labelled content outside each } \\
\text { of the stated ranges; none is more than } 10 \text { per cent of the labelled } \\
\text { amount below the stated amount at the final test time. }\end{array}$ \\
\hline L3 & 12 & $\begin{array}{l}\text { The average value of the } 24 \text { units }(\mathrm{L} 1+\mathrm{L} 2+\mathrm{L} 3) \text { lies within each of } \\
\text { the stated ranges, and is not less than the stated amount at the final } \\
\text { test time; not more than } 2 \text { of the } 24 \text { units are more than } 10 \text { per cent } \\
\text { of labelled content outside each of the stated ranges; not more than } \\
2 \text { of the } 24 \text { units are more than } 10 \text { per cent of labelled content } \\
\text { below the stated amount at the final test time, and none of the units } \\
\text { is more than } 20 \text { per cent of labelled content outside each of the } \\
\text { stated ranges or more than } 20 \text { per cent of labelled content below } \\
\text { the stated amount at the final test time. }\end{array}$ \\
\hline
\end{tabular}

Unless the results conform at either L1 or L2, continue testing through the three stages. Limits on the amounts of active substance dissolved are expressed in terms of the percentage of the labelled content. The limits embrace each value of $Q_{i}(D$ in $I P)$, the amount dissolved at each specified partial dosing interval. Where more than one range is specified, the acceptance criteria apply individually to each range [14, 18-20].

Table 9 Acceptance criteria for dissolution test of delayed-release or modified release tablet as per USP, BP, JP and IP.

\begin{tabular}{|c|c|c|}
\hline \multicolumn{3}{|c|}{ Acid Stage } \\
\hline Stage & Number of tablets tested & Acceptance Criteria \\
\hline A1 & 6 & No individual value exceeds $10 \%$ dissolved. \\
\hline $\mathrm{A} 2$ & 6 & $\begin{array}{l}\text { Average value of } 12 \text { units }(A 1+A 2) \text { is not greater than } 10 \% \\
\text { dissolved, and no unit is greater than } 25 \% \text { dissolved. }\end{array}$ \\
\hline A3 & 12 & $\begin{array}{l}\text { Average value of } 24 \text { units }(\mathrm{A} 1+\mathrm{A} 2+\mathrm{A} 3) \text { is not greater than } \\
10 \% \text { dissolved, and no unit is greater than } 25 \% \text { dissolved. }\end{array}$ \\
\hline
\end{tabular}

\begin{tabular}{|c|c|c|}
\hline \multicolumn{3}{|c|}{ Buffer Stage } \\
\hline Stage & Number of tablets tested & Acceptance Criteria \\
\hline B1 & 6 & Each unit is not less than $Q+5 \%$. \\
\hline B2 & 6 & $\begin{array}{l}\text { Average of } 12 \text { units }(B 1+B 2) \text { is equal to or greater than } Q \text {, and no } \\
\text { unit is less than } Q-15 \% \text {. }\end{array}$ \\
\hline B3 & 12 & $\begin{array}{l}\text { Average of } 24 \text { units }(B 1+B 2+B 3) \text { is equal to or greater than } Q \text {, not } \\
\text { more than } 2 \text { units are less than } Q-15 \% \text {, and no unit is less than } Q- \\
25 \% \text {. }\end{array}$ \\
\hline
\end{tabular}

Unless the results conform at either A1 or A2 and B1 or B2, continue testing through the three stages. According to JP, when the value of $Q$ or $D$ is not specified in individual monograph and if 1 or 2 tablets fail to comply within the 
requirements as in both acid and buffer stage, repeat the test on additional six tablets. To conform to the test, not less than 10 tablets out of 12 should meet the requirements [20]

\section{Conclusion}

The current review briefly recapitulates various in-processes and finished product quality control tests based on different compendial and non-compendial standards concerning quality attributes prior to their release into the market. In-process quality test is designed to assess problems arising at the time of manufacturing or to provide early admonition for quality and to scrutinizing processes for a product, to guarantee the production of medication of superior efficacy and safety consistently after batch to batch. These in-process controls are essential to make sure the quality of the product moreover we can lessen material, time, cost, repetition of processes by the implementation of inprocess quality test. The foremost objective of all pharmacopoeias is to manufacture good quality pharmaceutical for human wellbeing, though there is the trivial disparity in quality control tests as per Indian pharmacopoeia, British pharmacopoeia, Japanese Pharmacopoeia, European Pharmacopoeia, International and United state pharmacopoeia.

\section{Compliance with ethical standards}

\section{Acknowledgments}

We heartily acknowledge Biogain Remedies Pvt. Ltd., especially Abhishek Ghimire, Factory Operations Director for providing space, encouragement and needed things to carry out this work.

\section{Disclosure of conflict of interest}

The authors report no conflicts of interest. The authors alone are responsible for the content and writing of this article.

\section{References}

[1] Gupta VN and Kumar VP. (2015). A Review on quality by design approach (QBD) for Pharmaceuticals. International Journal of Drug Development and Research, 7(1), 52-60.

[2] Woodcock J. (2004). The concept of pharmaceutical quality. American Pharmaceutical Review, 7(60), 10-15.

[3] Mittal A, Priyadarshani K, Rathore RPS and Abhilasha. (2015). A Review on Comparative Study of In-process and Finished Product Quality Control Test for Sterile and Non-Sterile Dosage Form. International Journal of Institutional Pharmacy and Life Sciences, 5(2), 52-65.

[4] Fortunak JM, Souza RD, Kulkarni AA, King CL, Ellison T and Miranda LSM. (2014). Active pharmaceutical ingredients for antiretroviral treatment in low- and middle-income countries: a survey. Antivir Ther, 19(3), 1529.

[5] Rana TM, Salaria MR, Herani GM and Qureshi MA. (2009). Role of Quality Management inPharmaceutical Development: Evidence from Islamabad and Lahore. Indus Journal of Management and Social Sciences, 3(2), 99109.

[6] Aulton ME. (2001). Pharmaceutics-The science of dosage form design, Second edition. Churchill Livingstone.

[7] World Health Organization. (2011). WHO Technical Report Series, No. 961, 48th Report, Annex 3. World Health Organization, Geneva.

[8] Teja CH, Balamuralidhara V, Vinay S, Bhat RS and TMP Kumar. (2011). Comparative study of in-process and finished products quality control test of Indian Pharmacopoeia, British Pharmacopoeia, United State Pharmacopoeia for capsule and liquid orals. International Research Journal of Pharmacy, 2(9), 65-69.

[9] Mazumder B, Bhattacharya S and Yadav A. (2011). Total Quality Management in Pharmaceuticals: A Review. International Journal of PharmTech Research, 3(1), 365-375.

[10] Levi L, Walker GC and Pugsley LI. (2010). Quality Control of Pharmaceuticals. The Canadian Medical Association, 91(15), 96.

[11] Vinay S, Bhat SR, Balamuralidhara V and Kumar TMP. (2011). Comparative Study of In-process and Finished Products Quality Control Tests of IP, BP \& USP for Tablets. International Journal of Pharmacy Teaching \& Practices, 2(4), 176-183. 
[12] Lachman L, Lieberman HA and Kanig JL. (1987). The Theory and Practice of Industrial Pharmacy, Third edition. Varghese Publishing House, Dadar Bombay, 296-300.

[13] Allen LV. (2013). Remington: An Introduction to Pharmacy First edition. Pharmaceutical Press Lambeth High Street, London, 146.

[14] British Pharmacopoeia Commision. (2020). British Pharmacopoeia. British Pharmacopoeia Commision, Stationery Office, Great Britain.

[15] European Medicines agency. (2006). International Conference on Harmonisation (ICH) Guidelines Q3B (R2). Impurities in New drug Products. European Medicines agency, U.K.

[16] World Health Organization. (2014). Revision of Monograph on Tablets. World Health Organization, Geneva.

[17] Jr. LVA and Ansel HC. (2014). Ansel's Pharmaceutical Dosage Forms and Drug Delivery Systems, Tenth edition, Baltimore, Philadelphia, 271.

[18] United State Pharmacopoeia 40-National Formulary 35. (2017). Thirty Five edition. United State Pharmacopoeia Convention, Stationery Officer, USA.

[19] Indian Pharmacopoeia, Government of India, Ministry of Health and family Welfare. (2018). Eight edition. The Indian Pharmacopoeia Commision, Gaziabad, India.

[20] Society of Japanese Pharmacopoeia. (2016). The Japanese Pharmacopoeia, Sixteen edition. Pharmaceuticals and Medical Devices Agency, Japan.

[21] European Pharmacopoeia Comission. (2013). European Pharmacopoeia. Council of Europe, Europe.

[22] World Health Organization. (2003). The International Pharmacopoeia.. World Health Organization, Geneva.

\section{How to cite this article}

Ghimire P, Shrestha AC, Pandey S, Chapagain B and Dhakal S. (2020). Pharmacopoeial comparison of in-process and finished product quality control test for pharmaceutical tablets. GSC Biological and Pharmaceutical Sciences, 11(3), 155165 . 